\author{
Jinhua $\mathbf{L i}^{1}$ \\ Junying Liu $^{1,2}$ \\ Wenhui Lu' ${ }^{1}$ \\ Fangfang $\mathrm{Gao}^{1,2}$ \\ Liyan Wang ${ }^{1}$ \\ Jiping $\mathrm{Ma}^{3}$ \\ Huitao Liu' ${ }^{2}$ * \\ Chunyang Liao ${ }^{4}$ \\ Lingxin Chen ${ }^{1,2}$
${ }^{1}$ Key Laboratory of Coastal Environmental Processes and Ecological Remediation,
Research Center for Coastal
Environmental Engineering
Technology of Shandong
Province, Yantai Institute of
Coastal Zone Research, Chinese
Academy of Sciences, Yantai,
P. R. China
${ }^{2}$ College of Chemistry and Chemical Engineering, Yantai
University, Yantai, P. R. China
${ }^{3}$ School of Environmental and
Municipal Engineering, Qingdao
Technological University,
Qingdao, P. R. China
${ }^{4}$ State Key Laboratory of
Environmental Chemistry and
Ecotoxicology, Research Center
for Eco-Environmental Sciences,
Chinese Academy of Sciences,
Beijing, P. R. China

Received September 27, 2017

Revised April 1, 2018

Accepted April 16, 2018
Research Article

\section{Speciation analysis of mercury by dispersive solid-phase extraction coupled with capillary electrophoresis}

\begin{abstract}
A pretreatment method of dispersive solid-phase extraction (DSPE) along with backextraction followed by CE-UV detector was developed for the determination of mercury species in water samples. Sulfhydryl-functionalized $\mathrm{SiO}_{2}$ microspheres $\left(\mathrm{SiO}_{2}-\mathrm{SH}\right)$ were synthesized and used as DSPE adsorbents for selective extraction and enrichment of three organic mercury species namely ethylmercury (EtHg), methylmercury (MeHg), and phenylmercury (PhHg), along with L-cysteine (L-cys) containing hydrochloric acid as backextraction solvent. Several main extraction parameters were systematically investigated including sample $\mathrm{pH}$, amount of adsorbent, extraction and back-extraction time, volume of eluent, and concentration of hydrochloric acid. Under optimal conditions, good linearity was achieved with correlation coefficients over 0.9990 , in the range of $4-200 \mu \mathrm{g} / \mathrm{L}$ for $\mathrm{EtHg}$, and 2-200 $\mu \mathrm{g} / \mathrm{L}$ for $\mathrm{MeHg}$ and PhHg. The LODs were obtained of 1.07, 0.34, and $0.24 \mu \mathrm{g} / \mathrm{L}$ for EtHg, MeHg, and PhHg, respectively, as well as the LOQs were 3.57, 1.13, and $0.79 \mu \mathrm{g} / \mathrm{L}$, respectively, with enrichment factors ranging from 109 to 184 . Recoveries were attained with tap and lake water samples in a range of $62.3-107.2 \%$, with relative standard deviations of 3.5-10.1\%. The results proved that the method of $\mathrm{SiO}_{2}-\mathrm{SH}$ based DSPE coupled with CE-UV was a simple, rapid, cost-effective, and eco-friendly alternative for the determination of mercury species in water samples.
\end{abstract}

\section{Keywords:}

Capillary electrophoresis / Dispersive solid-phase extraction / Mercury species / Speciation analysis / UV detection

DOI 10.1002/elps.201800024

\section{Introduction}

The pollution of heavy metals has drawn widespread attention owing to their high toxicological effects and bioaccumulation properties. As one kind of common heavy metal in environment, mercury $(\mathrm{Hg})$ has different chemical existence forms, showing huge gap in the toxicity to human [1,2]. The organic forms of mercury such as methylmercury $(\mathrm{MeHg})$, ethylmercury (EtHg), and phenylmercury $(\mathrm{PhHg})$ have much more fatal impact than an inorganic mercury because of the

Correspondence: Professor Lingxin Chen, Key Laboratory of Coastal Environmental Processes and Ecological Remediation, Research Center for Coastal Environmental Engineering Technology of Shandong Province, Yantai Institute of Coastal Zone Research, Chinese Academy of Sciences, Hunhui Rd 17, Laishan District, Yantai 264003, P. R. China

E-mail: Ixchen@yic.ac.cn

Abbreviations: AFS, atomic fluorescence spectrometry; DLLME, dispersive liquid-liquid microextraction; DSPE, dispersive solid-phase extraction; EF, enrichment factor; LLLME, liquid-liquid-liquid microextraction; MPS, 3-mercaptopropyltrimethoxysilane; TEOS, tetraethyl orthosilicate lipophilicity and teratogenicity of organic ones [1-4]. Once entering the organism, the organic mercury is almost impossibly discharged from body. So, recognition and detection of the organic $\mathrm{Hg}$ is quite significant rather than determination of the total $\mathrm{Hg}$.

Chromatographic technologies currently available for separation and determination of mercury species generally include GC $[4,5]$, HPLC $[6,7]$, and CE [8-10]. The separation technologies are usually coupled with different types of detectors such as ICP-MS [11-13], UV $[14,15]$, and atomic fluorescence spectrometry (AFS) $[16,17]$. In recent decades, CE has boomed rapidly in element speciation analysis $[10,18]$, mainly attributed to its prominent advantages such as high separation efficiency, low sample/solvent consumption, varied separation modes, and short-analysis time [10, 18-22]. Due to the simplicity and low-cost of instrumentation, a UV absorbance detector is the most common detector integrated to commercial CE instruments. However, CE-UV suffers from a primary deficiency of low sensitivity, as the

\footnotetext{
*Additional corresponding author:Professor Huitao Liu E-mail: liuht-ytu@163.com

Color Online: See the article online to view Figs. 1, 2 and 4 in color.
} 
result of a low injection volume and narrow optical pathlength [21]. Two basic approaches can be adopted to resolve the sensitivity problem, either with special detectors that are more sensitive than UV such as ICP-MS [10], or with increased analyte amounts by using on column and/or off column preconcentration methods [23]. Consequently, developing high-efficiency enrichment techniques and methods for improvement in sensitivity can allow a wider application of CE-UV and avoid the use of complex and bulky instrumentation.

On the other hand, sample matrices in environment are usually complicated and contents of mercury species are usually at trace levels, which would render direct analysis quite difficult or scarcely possible. Direct injection of crude samples/extracts is usually not recommended, since complicated matrices can inhibit or enhance analytes' ionization or seriously pollute a separator/detector, and concentrations of analytes are too low to detect $[23,24]$. Accordingly, effective sample preparation/pretreatment steps before instrumental analysis are critical, aiming at elimination of matrix interfering agents and analyte preconcentration. For this regard, a number of pretreatment technologies/methods for the analysis of mercury species have been developed [10], including SPE [25, 26], stir bar sorptive extraction (SBSE) [5], dispersive liquid-liquid microextraction (DLLME) [14, 18, 27], liquid-liquid-liquid microextraction (LLLME) $[9,15]$, singledrop microextraction [28], dual-cloud point extraction [29], and so on. Dispersive SPE (DSPE) has recently gained popularity [30], in which adsorbents are directly added into sample matrices without packing in a column and conditioning, and then analytes are flushed off by elution solvent and finally the elution solvent is reserved and analyzed. DSPE can avoid tedious treatment in conventional SPE procedure, easy blockage of adsorption column, excessive solvent consumption as well as poor repeatability [31]. At the same time, one major drawback of DSPE is lack of selectivity, easily leading to undesirable consequences and lower detection sensitivity. So, selective adsorbents are highly desirable for DSPE [31, 32].

As is well known, Hg species can well interact with sulfhydryl groups $[3,10,18]$, which can be utilized for preparing selective adsorbents, such as sulfhydryl (or mercapto) functionalized silica particles [33-35]. The mercapto-silicarelated studies have been carried out and also applied to mercury measurement [36-38]. Therefore, in this work, we synthesized a kind of adsorbent named $\mathrm{SiO}_{2}-\mathrm{SH}$ by a facile sol-gel process followed by a simple functionalization procedure, based on the fact that mercury and sulfhydryl can form stable metal chelate complexes. And then the $\mathrm{SiO}_{2}-\mathrm{SH}$ microspheres were used as adsorbents of DSPE coupled with CE-UV for the simultaneous separation and determination of three organic mercury species. Several variables affecting DSPE efficiency were investigated in detail, including sample solution $\mathrm{pH}$, adsorbent amount, extraction and back-extraction time, and eluent composition and volume. Under the optimized conditions, the DSPE-CE method was well validated and successfully applied to real water sample analysis, demonstrating high sensitivity, repeatability, simplicity, rapidity, good practical feasibility, and environmental benignity.

\section{Materials and methods}

\subsection{Reagents and samples}

The standard solutions of $\mathrm{MeHg}$ and $\mathrm{PhHg}$ at a concentration of $1000 \mathrm{mg} / \mathrm{L}$ prepared by dissolving the appropriate amounts of the standards in $\mathrm{MeOH}$ were both purchased from Aladdin (Shanghai, China). EtHg standard solution at $60 \mathrm{mg} / \mathrm{L}$ was purchased from National Institute of Metrology (Beijing, China). Working solutions were prepared by stepwise diluting the stock solutions to the required concentrations using ultrapure water and all stored in refrigerator at $4^{\circ} \mathrm{C}$ before use. Tetraethyl orthosilicate (TEOS), sodium hydroxide $(\mathrm{NaOH})$, and L-cysteine (L-Cys) were all purchased from Sinopharm Chemical Reagent (Shanghai, China). 3-Mercaptopropyltrimethoxysilane (MPS) used as sulfhydrylization reagent was purchased from Sigma-Aldrich (Shanghai, China). Analytical grade ethanol and boric acid $\left(\mathrm{H}_{3} \mathrm{BO}_{3}\right)$ were purchased from Tianjin Kermel Chemical Reagent Factory (Tianjin, China). Deionized ultrapure water used throughout the work was produced by a Milli-Q Ultrapure water system (Millipore, Bedford, MA, USA). The $\mathrm{pH}$ measurement was performed through a pHs-3TC digital $\mathrm{pH}$ meter equipped with a combined glass-calomel electrode (Shanghai, China).

Lake water samples were collected using a teflon bottle from an artificial lake named Sanyuan Lake located in the schoolyard of Yantai University. Tap water samples were collected from our laboratory of Yantai Institute of Coastal Zone Research, after flowing for about 5 min when needed. The collected water samples were only simply filtrated through $0.45 \mu \mathrm{m}$ membrane (Tianjin Jinteng Experiment Equipment Ltd., Co., Tianjin, China) to remove possible impurity, and then were stored at $4^{\circ} \mathrm{C}$ in a refrigerator for use.

\subsection{Instrumentation and CE conditions}

Mercury determination was carried out by using a P/ACE MDQ CE system (Beckman Coulter, Fullerton, CA, USA) equipped with a diode-array detector. Bare fused-silica capillaries were used, which were purchased from Yongnian Photoconductive Fiber Factory (Hebei, China), with inner diameter of $75 \mu \mathrm{m}$, outer diameter of $375 \mu \mathrm{m}$, total length of $50.2 \mathrm{~cm}$, and effective length of $40 \mathrm{~cm}$. New capillaries were initialized with water $(10 \mathrm{~min}), 1.0 \mathrm{~mol} / \mathrm{L} \mathrm{NaOH}$ (40 min), water (10 $\mathrm{min})$, and running buffer (30 $\mathrm{min}$ ) for the first use. Before daily experiments, the capillary was reconditioned by rinsing with water $(2 \mathrm{~min}), 1.0 \mathrm{~mol} / \mathrm{L} \mathrm{NaOH}(10 \mathrm{~min})$, water (5 min), and running buffer (5 min) sequentially. Between two successive CE runs, the capillary was rinsed with the running buffer for $3 \mathrm{~min}$. 


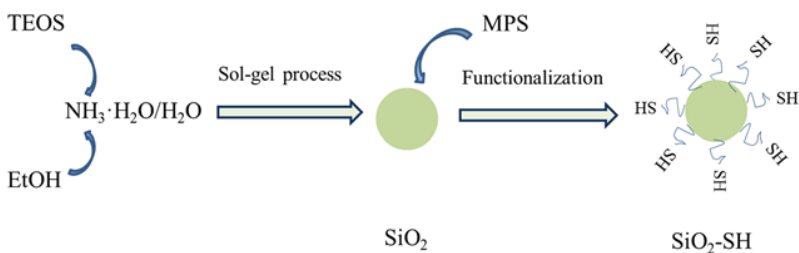

Figure 1. Schematic illustration of the preparation process for $\mathrm{SiO}_{2}-\mathrm{SH}$ microspheres.

The same CE separation conditions as our previous work [18] were below. The running buffer was consisted of $75 \mathrm{mmol} / \mathrm{L}_{3} \mathrm{BO}_{3}$ and $10 \% \mathrm{v} / \mathrm{v} \mathrm{MeOH}$ with $\mathrm{pH}$ of 9.0 , which was prepared freshly daily for use. Injection pressure of 0.5 psi for $5 \mathrm{~s}$, separation voltage of $+20 \mathrm{kV}$ and temperature of $25^{\circ} \mathrm{C}$ were employed. Before use, all electrolytes and samples were filtered through $0.45 \mu \mathrm{m}$ membranes. Except that, the detection wavelength was optimized and set at $228 \mathrm{~nm}$. Mercury species were identified by comparing/matching the migration times of mercury species between standards and tested samples, and by standard addition methods.

\subsection{Synthesis of sulfhydryl-functionalized $\mathrm{SiO}_{2}$ microspheres $\left(\mathrm{SiO}_{2}-\mathrm{SH}\right)$}

The whole preparation process of sulfhydryl-functionalized $\mathrm{SiO}_{2}$ microspheres was schematically shown in Fig. 1. Firstly, $\mathrm{SiO}_{2}$ microspheres were synthesized by a sol-gel process with hydrolysis of TEOS and aqueous ammonia $\left(\mathrm{NH}_{3} \cdot \mathrm{H}_{2} \mathrm{O}\right)$ used as catalyst, based on the Stöber method [39]. On the whole, ethanol $(30 \mathrm{~mL}), \mathrm{NH}_{3} \cdot \mathrm{H}_{2} \mathrm{O}(5 \mathrm{~mL})$, and ultrapure water $(50 \mathrm{~mL})$ were added sequentially to a $250 \mathrm{~mL}$ three-necked, round-bottom flask. The mixture solution was magnetically stirred for homogeneous dispersion followed by adding TEOS $(5 \mathrm{~mL}$ ) drop by drop with a constant-pressure dropping funnel, and it was kept stirring for $12 \mathrm{~h}$. Then the resultant mixture was centrifuged and washed thoroughly with ethanol for three times, and finally dried in a vacuum drying oven, powdered to particles.

Then, the obtained $\mathrm{SiO}_{2}$ microspheres were further functionalized using MPS as sulfhydrylization reagent. Certain amounts of $\mathrm{SiO}_{2}$ microspheres and ethanol $(100 \mathrm{~mL})$ were mixed in a flask with ultrasonic dissolving, followed by adding MPS. After stirring for $12 \mathrm{~h}$, sulfhydryl-functionalized $\mathrm{SiO}_{2}$ microspheres were obtained by centrifugation and washing with ethanol for three times. Finally, the modified microspheres were dried under vacuum and powdered to particles for use, named $\mathrm{SiO}_{2}-\mathrm{SH}$ for simplicity. As observed from image of scanning electron microscope (SEM, Hitachi $\mathrm{S}-4800 \mathrm{FE}-\mathrm{SEM}, 3 \mathrm{kV}$ ), the $\mathrm{SiO}_{2}-\mathrm{SH}$ microspheres were spherical with a diameter of about $165 \mathrm{~nm}$ and dispersed well.

\subsection{DSPE procedure}

Aqueous solution $(10 \mathrm{~mL}$ ) with the $\mathrm{pH}$ adjusted to 7.0 (by using $1 \mathrm{~mol} / \mathrm{L} \mathrm{HCl}$ or $1 \mathrm{~mol} / \mathrm{L} \mathrm{NaOH}$ ) containing three mercury species was placed into a $15 \mathrm{~mL}$ centrifuge tube with conical bottom, followed by adding sulfhydryl-functionalized $\mathrm{SiO}_{2}$ materials $(5 \mathrm{mg})$. After ultrasound, the mixture solution was shaken for $1 \mathrm{~h}$ at $200 \mathrm{rpm}$. Then, it was centrifuged for $5 \mathrm{~min}$ at $6500 \mathrm{rpm}$. The supernatant liquid was removed. $0.1 \% \mathrm{w} / \mathrm{v}$ L-Cys $(20 \mu \mathrm{L})$ containing $\mathrm{HCl}(0.05 \mathrm{mmol} / \mathrm{L})$ used as backextractant was mixed with the sedimentary phase. After sonification for about $1 \mathrm{~min}$, the mixture was centrifuged for $5 \mathrm{~min}$ at $7000 \mathrm{rpm}$. The supernatant liquid was taken out and prepared for CE analysis. Illustration of the whole DSPE procedure was shown in Fig. 2.

\section{Results and discussion}

\subsection{Condition optimization of $\mathrm{SiO}_{2}-\mathrm{SH}$ based DSPE}

The synthetic $\mathrm{SiO}_{2}-\mathrm{SH}$ microspheres were used as adsorbents and the solution of L-Cys containing $\mathrm{HCl}$ were served for elution. Several important parameters including sample $\mathrm{pH}$, amount of adsorbent, extraction time, back extraction, and desorption conditions were investigated to obtain the optimal extraction efficiency for the analysis of mercury species.

Sample $\mathrm{pH}$ is a significant parameter because it has close relationship with the existing forms of metal ions and then affects the interactions between the analytes and the adsorbents [40]. Hence, the effect of sample $\mathrm{pH}$ on extraction efficiency was investigated. The testing solution $\mathrm{pH}$ was adjusted in the range of 5.0-10.0. As can be seen from Fig. 3A, there was a slight increase of extraction efficiency with the increase of $\mathrm{pH}$ value from 5.0 to 7.0. The efficiency decreased obviously as the $\mathrm{pH}$ exceeded 7.0, which was probably owing to the interaction between mercury species and mainly existent hydroxyl. So, a $\mathrm{pH}$ value of 7.0 was chosen, and it was convenient that the tested samples could be directly analyzed without adjusting the $\mathrm{pH}$ values in the following work.

The amount of synthesized adsorbent was studied to obtain the optimal extraction efficiency. Different amounts of adsorbent ranging from 5 to $25 \mathrm{mg}$ were used to adsorb mercury species. The results in Fig. 3B showed that $5 \mathrm{mg}$ of adsorbent was sufficient for high extraction efficiency. Further increasing the amount to $25 \mathrm{mg}$ reduced the extraction efficiency, which was chiefly because the back-extraction solvent of L-Cys did not effectively extract the analytes from the adsorbent to the aqueous solutions. Therefore, $5 \mathrm{mg}$ adsorbent was chosen for further studies.

In the present DSPE procedure, extraction time was defined as the time of oscillation or shaking after the formation of suspension solution by ultrasonic. The influence of extraction time was investigated within $0-3 \mathrm{~h}$. According to the results, no significant change occurred as the extraction time increasing. This phenomenon can be attributed to the good dispersibility of $\mathrm{SiO}_{2}-\mathrm{SH}$ microspheres in aqueous solution. 


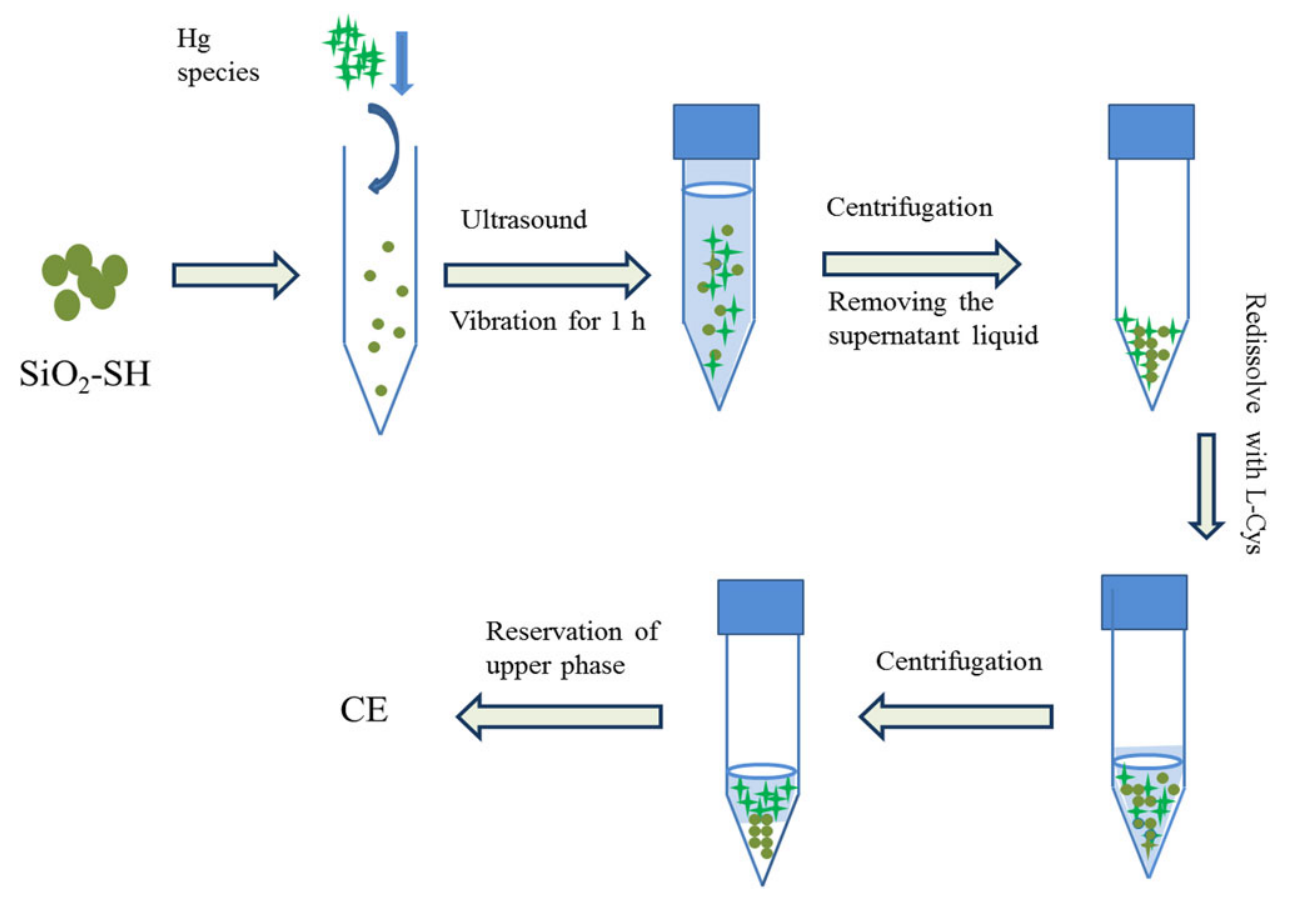

Figure 2. Illustration of the DSPE procedure.
Combining our comprehensive consideration, the extraction time was set at $1 \mathrm{~h}$.

According to our previous work [41], 0.1\% w/v L-Cys solution was selected as eluent to back extract the mercury species and form hydrophilic complexes for CE analysis. Then the effect of L-Cys volume was examined in the range of 20$120 \mu \mathrm{L}$ with $20 \mu \mathrm{L}$ interval. As shown in Fig. 3C, high extraction efficiency was attained with $20 \mu \mathrm{L}$ of L-Cys solution as eluent. The extraction efficiency decreased as the further increase of eluent volumes. It indicated $20 \mu \mathrm{L}$ eluent could effectively extract the mercury species with preferable enrichment factor. The volume less than $20 \mu \mathrm{L}$ was not studied for the fact that removal of the supernatant aqueous phase became more difficult with less volume of L-Cys solution. Hence, $20 \mu \mathrm{L}$ of $0.1 \% \mathrm{w} / \mathrm{v}$ L-Cys was selected for back extraction. In addition, the back extraction time was investigated by changing the ultrasonic time from 0.5 to $10 \mathrm{~min}$. There was no significant signal increasing with the time increasing. So, $1 \mathrm{~min}$ was chosen for the ultrasound-assisted back extraction.

In the procedure of desorption, the addition of hydrochloric acid in the eluent of L-Cys solution will be conducive to extract the analytes from the adsorbent materials [42]. A series of $0.1 \% \mathrm{w} / \mathrm{v}$ L-Cys solutions containing different concentrations of $\mathrm{HCl}$ ranging from $0-0.25 \mathrm{mmol} / \mathrm{L}$ were investigated. As shown in Fig. 3D, the optimal extraction efficiency was achieved in the $0.05 \mathrm{mmol} / \mathrm{L} \mathrm{HCl}$ and the peak area decreased with the concentrations further increasing. So, $0.05 \mathrm{mmol} / \mathrm{L}$ of $\mathrm{HCl}$ was used for the work.

Furthermore, during the DSPE procedure, the adsorption and extraction mechanism can be briefly deduced as below. Three organic mercury species could well interact with the sulfhydryl of $\mathrm{SiO}_{2}-\mathrm{SH}$ microspheres $[3,43]$. So, mercury species were adsorbed by the $\mathrm{SiO}_{2}-\mathrm{SH}$ adsorbent. Then, L-Cys was added as eluent (to destroy the former interactions) to produce hydrophilic mercury-L-Cys complexes $[18,29]$ for CE analysis.

\subsection{Method validation of the DSPE-CE}

Under the above-optimized conditions, the three types of mercury species could be resolved well via the proposed DSPECE. To validate the method, several main parameters were determined including linear range, LOD, LOQ, enrichment factors (EFs), precision, and anti-interference ability. Related data were summarized in Table 1 and 2. Good linearity between peak areas and concentrations was obtained in the range of $2-200 \mu \mathrm{g} / \mathrm{L}$ for $\mathrm{MeHg}, \mathrm{PhHg}$, and $4-200 \mu \mathrm{g} / \mathrm{L}$ for $\mathrm{EtHg}$, respectively, and the correlation coefficients were all over 0.9990 (Table 1). The LODs and LOQs were assessed based on signal-to-noise ratio of 3 and 10, respectively. As listed in Table 1, the LODs were 1.07, 0.34, and $0.24 \mu \mathrm{g} / \mathrm{L}$ for $\mathrm{EtHg}, \mathrm{MeHg}$, and $\mathrm{PhHg}$, respectively, as well as the LOQs were $3.57,1.13$, and $0.79 \mu \mathrm{g} / \mathrm{L}$. The present sensitivity meets trace analysis requirements and can contribute to mercury species detection in water samples especially industrial and sanitary wastewater. The EF values were calculated via the ratio of the analyte concentration in the sedimented phase to the initial aqueous sample concentration, providing 109 , 184, and 120 for EtHg, MeHg, and $\mathrm{PhHg}$, respectively, and showing high enrichment ability. Moreover, as seen from Table 2, the RSDs for intraday precisions in terms of migration time and peak area were less than 0.18 and $5.12 \%$, 

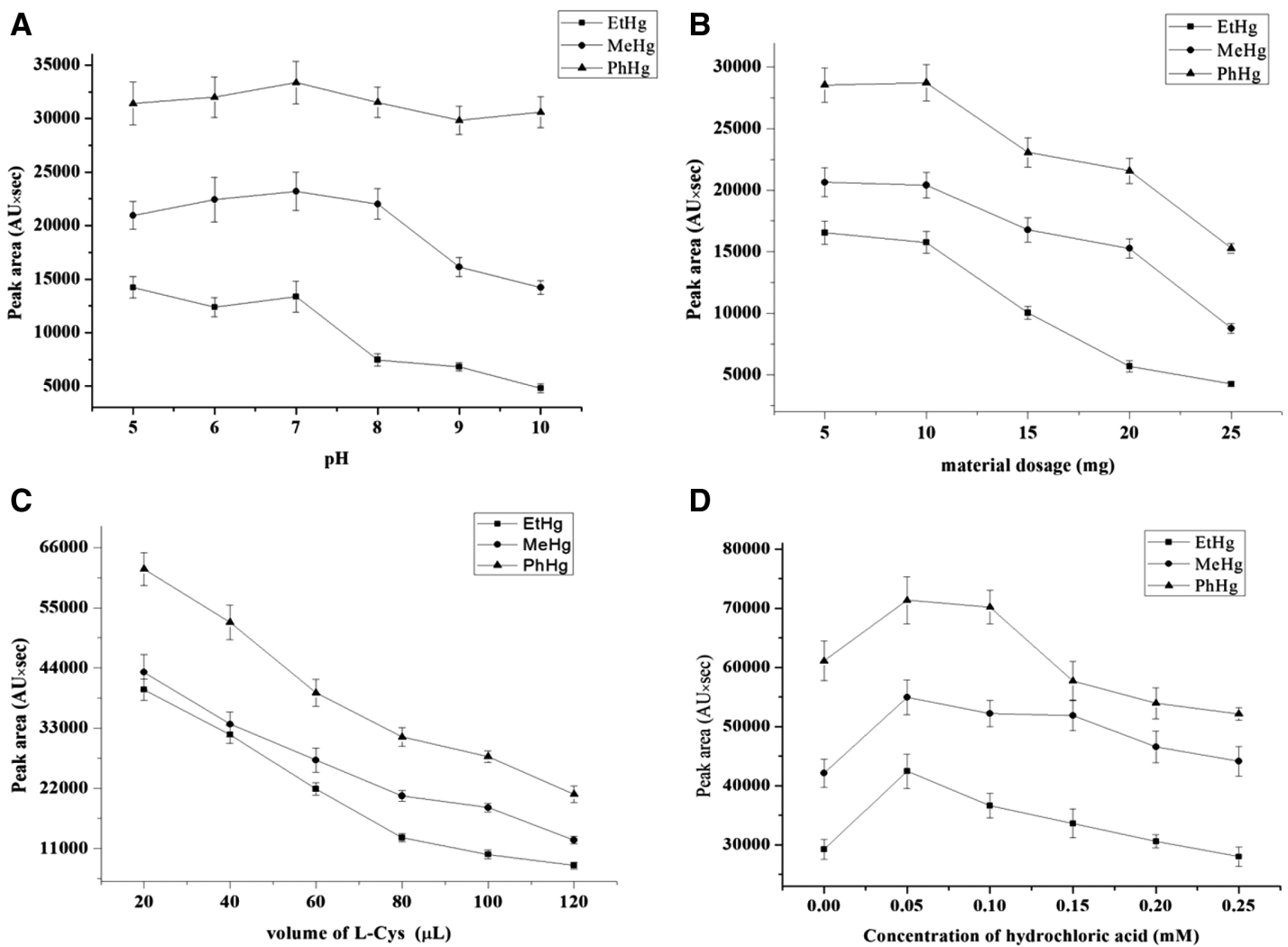

Figure 3. Effects of $\mathrm{pH}(\mathrm{A})$, material dosage (B), L-Cys volume (C), and concentration of hydrochloric acid (D) on DSPE of mercury species. Five parallel experiments were carried out $(n=5)$. CE conditions: injection pressure, 0.5 psi for $5 \mathrm{~s}$; separation voltage $+20 \mathrm{kV}$; detecion wavelength, $228 \mathrm{~nm}$; running buffer, $10 \mathrm{mM} \mathrm{H}_{3} \mathrm{BO}_{3}$, and $10 \% \mathrm{v} / \mathrm{v} \mathrm{MeOH}$ adjusted to $\mathrm{pH} 9.0$ with $1 \mathrm{~mol} / \mathrm{L} \mathrm{NaOH}$.

Table 1. Parameters of analytical performance of the optimized DSPE-CE for mercury species

\begin{tabular}{|c|c|c|c|c|c|c|c|}
\hline $\mathrm{Hg}$ species & Slope (RSD $\left.{ }^{\mathrm{a}}, \%\right)$ & Intercept (RSD, \%) & Linear range $(\mu \mathrm{g} / \mathrm{L})$ & $r$ & $\operatorname{LOD}(\mu \mathrm{g} / \mathrm{L})$ & LOO ( $\mu \mathrm{g} / \mathrm{L})$ & $\mathrm{EF}$ \\
\hline $\mathrm{EtHg}$ & $182.27(4.20)$ & $-868.99(431.63)$ & $4-200$ & 0.9992 & 1.07 & 3.57 & 109 \\
\hline $\mathrm{MeHg}$ & $290.62(4.80)$ & $-281.20(398.59)$ & $2-200$ & 0.9994 & 0.34 & 1.13 & 184 \\
\hline $\mathrm{PhHg}$ & $338.46(7.39)$ & $256.88(693.60)$ & $2-200$ & 0.9990 & 0.24 & 0.79 & 120 \\
\hline
\end{tabular}

a) $\mathrm{RSD}, n=5$.

Table 2. Precision of migration time and peak area for the determination of organic mercury by DSPE-CE

\begin{tabular}{llllll}
\hline Hg species & \multicolumn{2}{l}{$\operatorname{RSD}(\%, n=5)$} & & \\
\cline { 2 - 3 } & \multicolumn{2}{l}{ Intraday } & & \multicolumn{2}{l}{ Interday } \\
\cline { 2 - 3 } \cline { 5 - 6 } & Migration time & Peak area & & Migration time & Peak area \\
\hline $\mathrm{EtHg}$ & 0.18 & 3.37 & & 1.58 & 6.89 \\
$\mathrm{MeHg}$ & 0.14 & 3.29 & & 1.63 & 5.59 \\
$\mathrm{PhHg}$ & 0.13 & 5.12 & & 1.63 & 8.36 \\
\hline
\end{tabular}

respectively. As well as, the RSDs for the interday precisions were in the range of $1.58-1.63 \%$ for migration time and 5.59$8.36 \%$ for peak area. Consequently, the method was highly sensitive and capable of accurate quantification of organic mercury.
Furthermore, the interference effects of the possibly coexisting ions were examined by using some common alkali and alkaline earth metal ions $\left(\mathrm{Na}^{+}, \mathrm{K}^{+}\right.$, and $\left.\mathrm{Mg}^{2+}\right)$ and heavy metal ions $\left(\mathrm{Co}^{2+}, \mathrm{Pb}^{2+}, \mathrm{Cd}^{2+}, \mathrm{Zn}^{2+}\right.$, and $\left.\mathrm{Cu}^{2+}\right)$ in water samples. Under the optimal conditions, the assays were performed by spiking appropriate amounts of interfering ions (individual or mixture) to $10 \mathrm{~mL}$ solutions containing three types of mercury species at the concentration of $50 \mu \mathrm{g} / \mathrm{L}$ individual. As shown in Fig. 4, the obtained results (recoveries within 92.3-99.8\%) showed that 100 times $(5000 \mu \mathrm{g} / \mathrm{L})$ higher of $\mathrm{Na}^{+}, \mathrm{K}^{+}$, and $\mathrm{Mg}^{2+}$, respectively, ten times $(500 \mu \mathrm{g} / \mathrm{L})$ higher of $\mathrm{Co}^{2+}, \mathrm{Pb}^{2+}, \mathrm{Cd}^{2+}, \mathrm{Zn}^{2+}$, and $\mathrm{Cu}^{2+}$, respectively, and even their mixture of all the eight ions had no significant interferences on the mercury determination. Therefore, the developed DSPE-CE was highly selective and reliable for the determination of mercury species, indicating great application potentials in real water samples. 


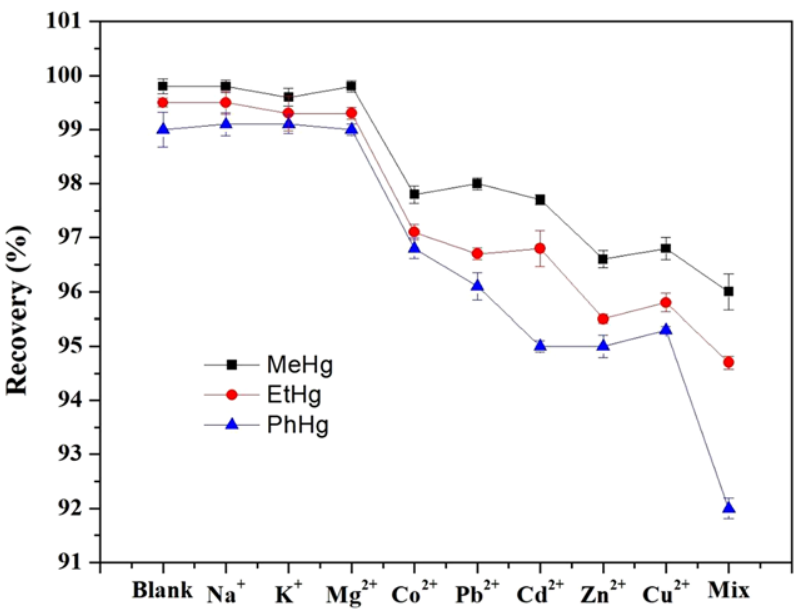

Figure 4. Interference effects of possible coexisting ions on the determination of mercury species by DSPE-CE. Experimental conditions: three mercury species, $50 \mu \mathrm{g} / \mathrm{L}$ individual; $\mathrm{Na}^{+}, \mathrm{K}^{+}$, and $\mathrm{Mg}^{2+}, 5000 \mu \mathrm{g} / \mathrm{L}$ individual; $\mathrm{Co}^{2+}, \mathrm{Pb}^{2+}, \mathrm{Cd}^{2+}, \mathrm{Zn}^{2+}$, and $\mathrm{Cu}^{2+}$, $500 \mu \mathrm{g} / \mathrm{L}$ individual; mixture, $\mathrm{Na}^{+}, \mathrm{K}^{+}$, and $\mathrm{Mg}^{2+}, 5000 \mu \mathrm{g} / \mathrm{L}$ individual, together with $\mathrm{Co}^{2+}, \mathrm{Pb}^{2+}, \mathrm{Cd}^{2+}, \mathrm{Zn}^{2+}$, and $\mathrm{Cu}^{2+}, 500 \mu \mathrm{g} / \mathrm{L}$ individual. Blank means no addition of the above-mentioned ions. Five parallel experiments were carried out $(n=5)$.

\subsection{Applications of the validated DSEP-CE to real water samples and method performance comparison}

To further evaluate the practical application of the validated method, tap water, and lake water were analyzed under the optimal conditions of DSPE-CE. Their typical electropherograms were shown in Fig. 5. As observed, none of mercury species endogenous were detected in the two kinds of water samples (curve a). For the spiked water samples, three resolved peaks were obviously demonstrated, corresponding to $\mathrm{EtHg}, \mathrm{MeHg}$, and $\mathrm{PhHg}$, respectively (curve b), indicating the selective enrichment ability and good cleanup effect of DSPE. Table 4 lists the recoveries of the two water samples by adding three levels of the three organic mercury standards. As shown from the table, recoveries were in a range of $62.3-107.2 \%$ with RSDs lower than $10.2 \%$. It could be concluded that the developed DSPE-CE method was practically applicable for the simultaneous enrichment, separation, and determination of the three organic species at trace levels in real water samples.

Method performance of the validated DSPE-CE for mercury speciation analysis was compared especially in LODs and EFs with other reported CE-hyphenated or HPLC-hyphenated methods, as summarized in Table $3[7,8,11,14,15,18$, $25,29,44]$. As can be seen from the table, our DSPE-CEUV method presents the LODs lower than [29], comparable to $[11,14,15,18,25,44]$, or higher than $[7,8]$, as well as the EFs higher than [29], comparable to [18], or lower than $[15,44]$. Meanwhile, other advantages/drawbacks of the different approaches from the literatures can be noticed as: the reported LLME [7, 14, 15, 18, 44], LPE [29], and SPE [25] based methods usually require certain amounts of harmful organic solvents; the method of MAE coupled with CE-ICPMS offers higher sensitivity but needs longer time (25 $\mathrm{min})$ to obtain baseline separation with the more expensive instrument [8]; LPE coupled with HPLC-ICP-MS method requires amounts of toxic organic reagents and high cost instrument [11]. Excitingly, our present method only needs less $5.5 \mathrm{~min}$ to attain baseline separation of the three organic mercury species. More importantly, in our method, organic solvent is almost free since working solutions were prepared by diluting the $\mathrm{MeOH}$ stock solution with ultrapure water. This is superior to the abovementioned approaches, considering they all use more or less toxic organic reagents. Therefore, on the whole, our developed $\mathrm{SiO}_{2}-\mathrm{SH}$ based DSPE coupled with CE-UV possessed remarkable advantages such as highly selective extraction efficiency, high sensitivity, shorter analysis time, and simplicity, rapidity, cost-saving, and eco-friendliness, as well as great practical feasibility.
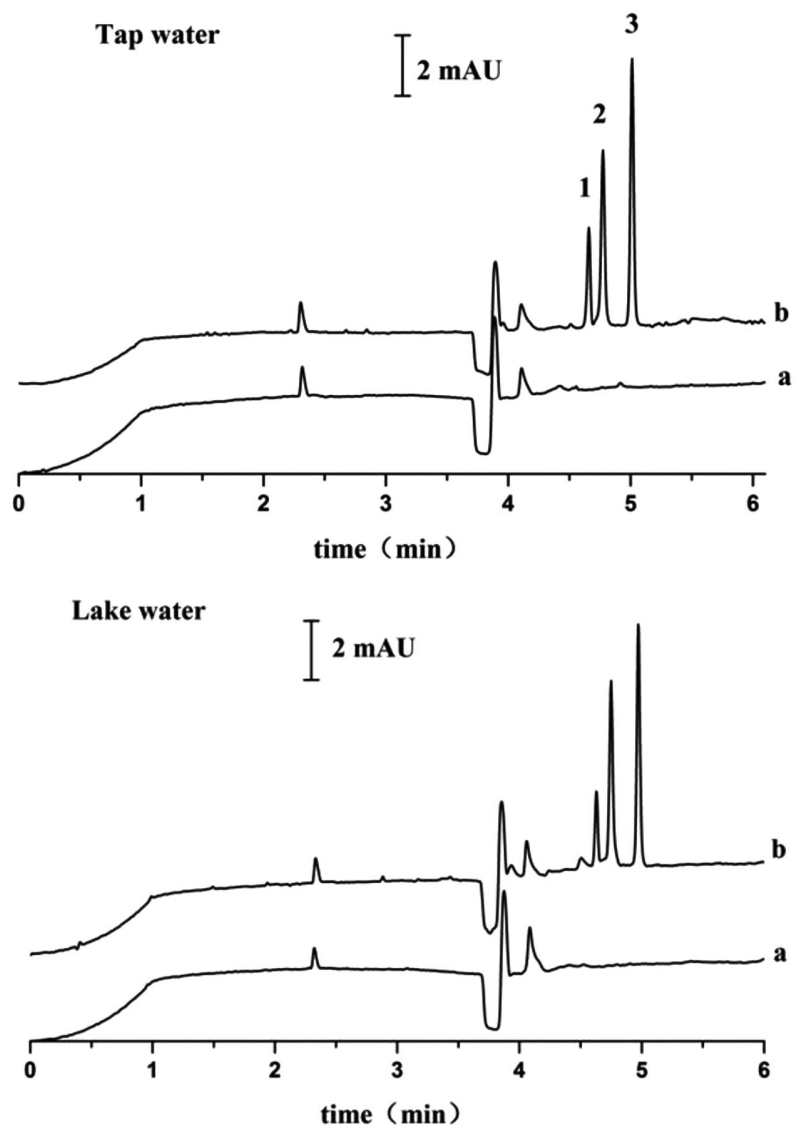

Figure 5. Typical electropherograms of the blank (A) and spiked (B) real water samples after DSPE with the concentration of $50 \mu \mathrm{g} / \mathrm{L}$ for EtHg, MeHg, and PhHg. Peak identification: 1, 2, and 3 corresponds to $\mathrm{EtHg}$, MeHg, and $\mathrm{PhHg}$, respectively. The optimal DSPE condition: sample volume, $10 \mathrm{~mL} ; 5 \mathrm{mg}$ adsorbing material; $0.1 \% \mathrm{w} / \mathrm{v} \mathrm{L-Cys}(20 \mu \mathrm{L})$ containing $0.05 \mathrm{mmol} / \mathrm{L}$ hydrochloric acid used as eluent. CE conditions were the same as Fig. 3. 
Table 3. Comparison of mercury speciation analysis based on methods of CE and HPLC

\begin{tabular}{|c|c|c|c|c|}
\hline Detection technique & Pretreatment technique & $\operatorname{LOD}(\mu \mathrm{g} / \mathrm{L})$ & $\mathrm{EF}^{\mathrm{a})}$ & Ref \\
\hline CE-UV & DSPE & $1.07,0.34,0.24$ & $109,184,120$ & This work \\
\hline CE-UV & DLLME & $1.62,1.79,0.23$ & $118,102,547$ & 18 \\
\hline CE-ICP-MS & $M A E^{b)}$ & $0.021(\mathrm{MeHg}), 0.032(\mathrm{EtHg})$ & - & 8 \\
\hline CE-UV & $\mathrm{dCPE} \mathrm{E}^{\mathrm{C})}$ & $45.2,47.5,4.1$ & $17,15,45$ & 29 \\
\hline CE-UV & LLLME & $0.94(\mathrm{MeHg}), 0.43(\mathrm{PhHg})$ & 324,210 & 15 \\
\hline HPLC-ICP-MS & $\mathrm{LPE}^{\mathrm{d})}$ & $0.8,0.5,1.0$ & - & 11 \\
\hline HPLC-UV & HF-LLLME ${ }^{\mathrm{e}}$ & $0.7,3.8,0.3$ & $215,120,350$ & 44 \\
\hline HPLC-CVAFS ${ }^{f)}$ & VALLMEg) & $0.057(\mathrm{EtHg}), 0.028(\mathrm{MeHg})$ & - & 7 \\
\hline HPLC-AFS & SPE & $1.4,4.3,0.8$ & - & 25 \\
\hline HPLC-UV & DLLME & $0.96(\mathrm{MeHg}), 1.91(\mathrm{PhHg})$ & 114,106 & 14 \\
\hline
\end{tabular}

a) Sequence of the analytes: EtHg, MeHg, PhHg.

b) Microwave-assisted extraction.

c) Dual-cloud point extraction.

d) Liquid phase extraction.

e) Hollow fiber-based liquid-liquid-liquid microextraction.

f) HPLC-vapor generation atomic fluorescence spectrometry

g) Vortex-assisted liquid-liquid microextraction.

Table 4. Recovery and precision of the developed DSPE-CE method used for real water samples $(n=5)$

\begin{tabular}{|c|c|c|c|c|c|c|c|}
\hline \multirow{2}{*}{$\begin{array}{l}\mathrm{Hg} \\
\text { species }\end{array}$} & \multirow{2}{*}{$\begin{array}{l}\text { Added } \\
(\mu \mathrm{g} / \mathrm{L})\end{array}$} & \multicolumn{3}{|l|}{ Tap water } & \multicolumn{3}{|l|}{ Lake water } \\
\hline & & Found $\pm S D(\mu \mathrm{g} / \mathrm{L})$ & Recovery (\%) & RSD (\%) & Found $\pm \mathrm{SD}(\mu \mathrm{g} / \mathrm{L})$ & Recovery (\%) & RSD (\%) \\
\hline \multirow[t]{3}{*}{ EtHg } & 10 & $8.8 \pm 0.8$ & 88.4 & 9.8 & $7.73 \pm 0.8$ & 77.3 & 10.1 \\
\hline & 50 & $42.1 \pm 2.5$ & 84.1 & 5.9 & $34.8 \pm 2.8$ & 69.6 & 8.0 \\
\hline & 100 & $94.3 \pm 4.8$ & 94.3 & 5.1 & $70.1 \pm 3.7$ & 70.1 & 5.3 \\
\hline \multirow[t]{3}{*}{$\mathrm{MeHg}$} & 5 & $4.6 \pm 0.3$ & 91.8 & 7.0 & $4.1 \pm 0.3$ & 82.8 & 6.1 \\
\hline & 50 & $53.6 \pm 2.5$ & 107.2 & 4.7 & $44.2 \pm 2.6$ & 88.3 & 5.8 \\
\hline & 100 & $90.7 \pm 5.8$ & 90.7 & 6.4 & $88.6 \pm 5.9$ & 88.6 & 6.7 \\
\hline \multirow[t]{3}{*}{$\mathrm{PhHg}$} & 5 & $3.2 \pm 0.3$ & 64.1 & 9.8 & $3.1 \pm 0.3$ & 62.3 & 8.5 \\
\hline & 50 & $52.9 \pm 3.5$ & 105.8 & 6.7 & $42.3 \pm 2.7$ & 84.5 & 6.3 \\
\hline & 100 & $100.6 \pm 6.3$ & 100.6 & 6.3 & $106.5 \pm 3.7$ & 106.5 & 3.5 \\
\hline
\end{tabular}

\section{Concluding remarks}

In conclusion, a synthetic material of $\mathrm{SiO}_{2}-\mathrm{SH}$ microsphere was firstly used as DSPE adsorbent for the simultaneous extraction and enrichment of mercury species. The method of DSPE combined with CE-UV enabled good analytical performances with high sensitivity, short separation time, and high EFs, and had been successfully applied to real water samples. Moreover, much less sample and reagent consumption, low operating cost, water-phase extraction system, and moderate CE separation conditions, made our method a valuable alternative to the speciation analysis of mercury. In view of the advantages, further explorations on smartly devising and synthesizing green adsorption/extraction materials for suitable extraction techniques will provide promising perspectives for speciation analysis of heavy metals by using CE. Furthermore, continuous efforts should be devoted into the various combinations of versatile off/online enrichment techniques for speciation analysis in complicated matrices, potentially offering higher CE sensitivity and satisfying green sustainable development.
This work was financially supported by the National Defence Science and Technology Innovation Project of Chinese Academy of Sciences (CXJJ-16M254), the National Natural Science Foundation of China (21477160, 21275158, 51573155, 21522706), and the Natural Science Foundation of Shandong Province of China (ZR2016DB07, ZR2016BL25).

The authors have declared no conflict of interest.

\section{References}

[1] Clarkson, T. W., Magos, L., Crit. Rev. Toxicol. 2006, 36, 609-662.

[2] Kirka, J. L., Lehnherrb, I., Anderssonc, M., Brauned, B. M., Chane, L., Dastoorf, A. P., Durnfordg, D., Gleasona, A. L., Losetoh, L. L., Steffeni, A., Louisj, V. L. S., Environ. Res. 2012, 119, 64-87.

[3] Chen, L., Li, J. H., Chen, L. X., ACS Appl. Mater. Interfaces 2014, 6, 15897-15904.

[4] Duarte, F. A., Soares, B. M., Vieira, A. A., Pereira, E. R., Maciel, J. V., Caldas, S. S., Primel, E. G., Anal. Chem. 2013, 85, 5015-5022. 
[5] Ito, R., Kawaguchi, M., Sakui, N., Honda, H., Okanouchi, N., Saito, K., Nakazawa, H., J. Chromatogr. A 2008, 1209, 267-270.

[6] Cheng, H. Y., Wu, C. L., Shen, L. H., Liu, J. H., Xu, Z. G., Anal. Chim. Acta 2014, 828, 9-16.

[7] Leng, G., Yin, H., Li, S. B., Chen, Y., Dan, D. Z., Talanta 2012, 99, 631-636.

[8] Zhao, Y. Q., Zheng, J. P., Fang, L., Lin, Q., Wu, Y. N., Xue, Z. M., Fu, F. F., Talanta 2012, 89, 280-285.

[9] Li, P. J., Zhang, X., Hu, B., J. Chromatogr. A 2011, 1218, 9414-9421.

[10] Timerbaev, A. R., Chem. Rev. 2013, 113, 778-812.

[11] dos Santos, J. S., de la Guardia, M., Pastor, A., dos Santos, M. L. P., Talanta 2009, 80, 207-211.

[12] de Souza, S. S., Campiglia, A. D., Barbosa, F., Anal. Chim. Acta 2013, 761, 11-17.

[13] Chen, X. P., Han, C., Cheng, H. Y., Wang, Y. C., Li, J. H., Xu, Z. G., Hu, L., J. Chromatogr. A 2013, 1314, 86-93.

[14] Gao, Z. B., Ma, X. G., Anal. Chim. Acta 2011, 702, 50-55.

[15] Fan, Z. F., Liu, X. J., J. Chromatogr. A 2008, 1180, 187-192.

[16] Liang, L. N., Jiang, G. B., Liu, J. F., Hu, J. T., Anal. Chim. Acta 2003, 477, 131-137.

[17] Wu, L., Long, Z., Liu, L. W., Zhou, Q., Lee, Y. I., Zheng, C. B., Talanta 2012, 94, 146-151.

[18] Yang, F. F., Li, J. H., Lu, W. H., Wen, Y. Y., Cai, X. Q., You, J. M., Ma, J. P., Ding, Y. J., Chen, L. X., Electrophoresis 2014, 35, 474-481.

[19] Rodriguez, J. A., Ibarra, I. S., Miranda, J. M., Barrado, E., Santos, E. M., Anal. Methods 2016, 8, 8466-8473.

[20] Li, J. H., Cai, Z. W., Talanta 2008, 77, 331-339.

[21] Felhofer, J. L., Scida, K., Penick, M., Willis, P. A., Garcia, C. D., Talanta 2013, 115, 688-693.

[22] Li, J. H., Chan, W., Cai, Z. W., Electrophoresis 2009, 30, 1790-1797.

[23] Wen, Y.Y., Li, J. H., Ma, J. P., Chen, L. X., Electrophoresis 2012, 33, 2933-2952.

[24] Wang, X., Ye, N. S., Electrophoresis 2017, 38, 3059-3078.
[25] Margetinova, J., Houserova-Pelcova, P., Kuban, V., Anal. Chim. Acta 2008, 615, 115-123.

[26] Yin, Y. G., Chen, M., Peng, J. F., Liu, J. F., Jiang, G. B., Talanta 2010, 81, 1788-1792.

[27] Jia, X. Y., Han, Y., Liu, X. L., Duan, T. C., Chen, H. T., Spectrochim. Acta Part B 2011, 66, 88-92.

[28] Pena-Pereira, F., Lavilla, I., Bendicho, C., Vidal, L., Canals, A., Talanta 2009, 78, 537-541.

[29] Yin, X. B., J. Chromatogr. A 2007, 1154, 437-443.

[30] Chen, L. X., Wang, X. Y., Lu, W. H., Wu, X. O., Li, J. H., Chem. Soc. Rev. 2016, 45, 2137-2211.

[31] Xiong, H. H., Wu, X. Q., Lu, W. H., Fu, J. O., Peng, H. L., Li, J. H., Wang, X. Y., Xiong, H., Chen, L. X., Talanta 2018, $176,187-194$.

[32] Wen, Y. Y., Chen, L., Li, J. H., Liu, D. Y., Chen, L. X., TrAC Trends Anal. Chem. 2014, 59, 26-41.

[33] Yuan, J. J., Wan, D. C., Yang, Z. L., J. Phys. Chem. C 2008, $112,17156-17160$.

[34] Lu, Z. D., Sun, L., Nguyen, K., Gao, C., Yin, Y. D., Langmuir 2011, 27, 3372-3380.

[35] Guo, B., Deng, F., Zhao, Y., Luo, X. B., Luo, S. L., Au, C. T., Appl. Surf. Sci. 2014, 292, 438-446.

[36] Delacote, C., Gaslain F. O. M., Lebeau, B., Walcarius, A., Talanta 2009, 79, 877-886.

[37] Cheng, H. Y., Wu, C. L., Liu, J. H., Xu, Z. G., RSC Adv. 2015, 5, 19082-19090.

[38] Zhao, W, Song, B, Tao, J, Zhang, J. M., Huang, M. J., Wang, C., Gou, M. L., J. Nanomater. 2016, 9758264.

[39] Stöber, W., Fink, A., Bohn, E., J. Colloid Interface Sci. 1968, 26, 62-69.

[40] Chai, W. B., Wang, H. J., Zhang, Y., Ding, G. S., Talanta 2016, 149, 13-20.

[41] Li, J. H., Lu, W. H., Ma, J. P., Chen, L. X., Microchim. Acta 2011, 175, 301-308.

[42] Bai, X. H., Fan, Z. F., Microchim. Acta 2010, 170, 107-112.

[43] Yan, X. P., Li, Y., Jiang, Y., Anal. Chem. 2003, 75, 2251-2255.

[44] Xia, L. B., Hu, B., Wu, Y. L., J. Chromatogr. A 2007, 1173, $44-51$. 